ISSN: 1948-9900

(C)2013 Science Publications

doi:10.3844/amjnsp.2013.25.38 Published Online 4 (1) 2013 (http://www.thescipub.com/ajn.toc)

\title{
Immune-Based Therapies for Spinal Cord Injury
}

\author{
${ }^{1,2}$ Basem I. Awad, ${ }^{1}$ Davina V. Gutierrez and ${ }^{1}$ Michael P. Steinmetz \\ ${ }^{1}$ Department of Neurosciences, Metro Health Medical Center, \\ School of Medicine, Cleveland, OH 44109, United States \\ ${ }^{2}$ Department of Neurosurgery, School of Medicine, Mansoura University, Mansoura, Egypt
}

Received 2013-01-23, Revised 2013-02-05; Accepted 2013-04-17

\begin{abstract}
Traumatic Spinal Cord Injury (SCI) results in both focal and diffuse spinal cord pathologies that are exacerbated by an inflammatory response after the initial injury. Resident and infiltrating immune cells contribute significantly to the growth-refractory environment near the lesion and can intensify damage to spared tissue, resulting in impaired spontaneous functional recovery. Numerous studies have demonstrated that several immunomodulatory therapies administered after experimental SCI may be beneficial in promoting functional recovery. In this review, we focus on the therapeutic potential of the most abundant immune-based therapies e.g., rolipram, liposomal clodronate and TNF- $\alpha$ based therapy including etanercept, thalidomide and adenosine A1 receptor therapy their contribution to eliminating secondary damage and promoting recovery after SCI.
\end{abstract}

Keywords: Spinal Cord Injury, Immunomodulatory Therapy, Neuroprotection, Rolipram, Liposomal Clodronate, TNF- $\alpha$ Based Therapy

\section{INTRODUCTION}

Traumatic SCI causes severe and often permanent neurological deficits due to the loss of descending motor and ascending sensory axonal pathways and subsequent demyelination (Bunge et al., 1993). The initial primary mechanical insult to the spinal cord includes compression, contusion, shearing and laceration and is followed by a series of destructive cellular processes, known as secondary injury, that accentuate tissue damage at and beyond the original site of trauma (Tator and Fehlings, 1991; Young, 1993; Schwab and Bartholdi, 1996; Sekhon and Fehlings, 2001; Jacobs and Fehlings, 2003; Stys, 2004) (Fig. 1).

The cascade of secondary injury events is primarily mediated by a robust cellular inflammatory response (Dusart and Schwab, 1994; Popovich et al., 1997; Keane et al., 2006) that involves macrophage and microglial activation (Blight, 1992; Popovich et al., 1999) and chemokine and cytokine production. Neutrophils are the first circulating leukocytes to infiltrate sites of SCI ( 2 h-3 days post-SCI) (Carlson et al., 1998; Fleming et al., 2006; Kigerl et al., 2006;
Nguyen et al., 2008; Stirling and Yong, 2008). Monocyte-derived macrophages infiltrate 2 days after neutrophils and help clear apoptotic neutrophils from the lesion (Savill et al., 1989; Stirling and Yong, 2008). This custodial function of macrophages may be necessary for inducing a subset of functions that include release of resolvins and protectins to suppress further neutrophil recruitment (Nathan, 2006). Unlike neutrophils, macrophages persist in human and mouse SCI lesions as long as any study has examined, months in mice and years in humans (Popovich et al., 2003; Fleming et al., 2006; Kigerl et al., 2006; Chang, 2007). The nonspecific microbicidal activity of neutrophils and monocytes/macrophages can be destructive to host tissue after SCI; both cell types release proteases (e.g., matrix metalloproteases) and oxidative metabolites that can damage cells and compromise the blood-spinal cord barrier (Noble et al., 2002; Scholz et al., 2007).

Indeed, SCI pathology is reduced and spontaneous recovery of neurological function (motor, sensory and autonomic) is improved when the activation of bloodderived leukocytes is restricted (Giulian and Robertson, 1990; Blight, 1994; Taoka et al., 1997; Popovich et al., 1999; Gris et al., 2004).

Corresponding Author:Michael P. Steinmetz, Department of Neuroscience, Metro Health Medical Center, School of Medicine, Cleveland, OH 44109, United States Tel: (216)-778-4386 


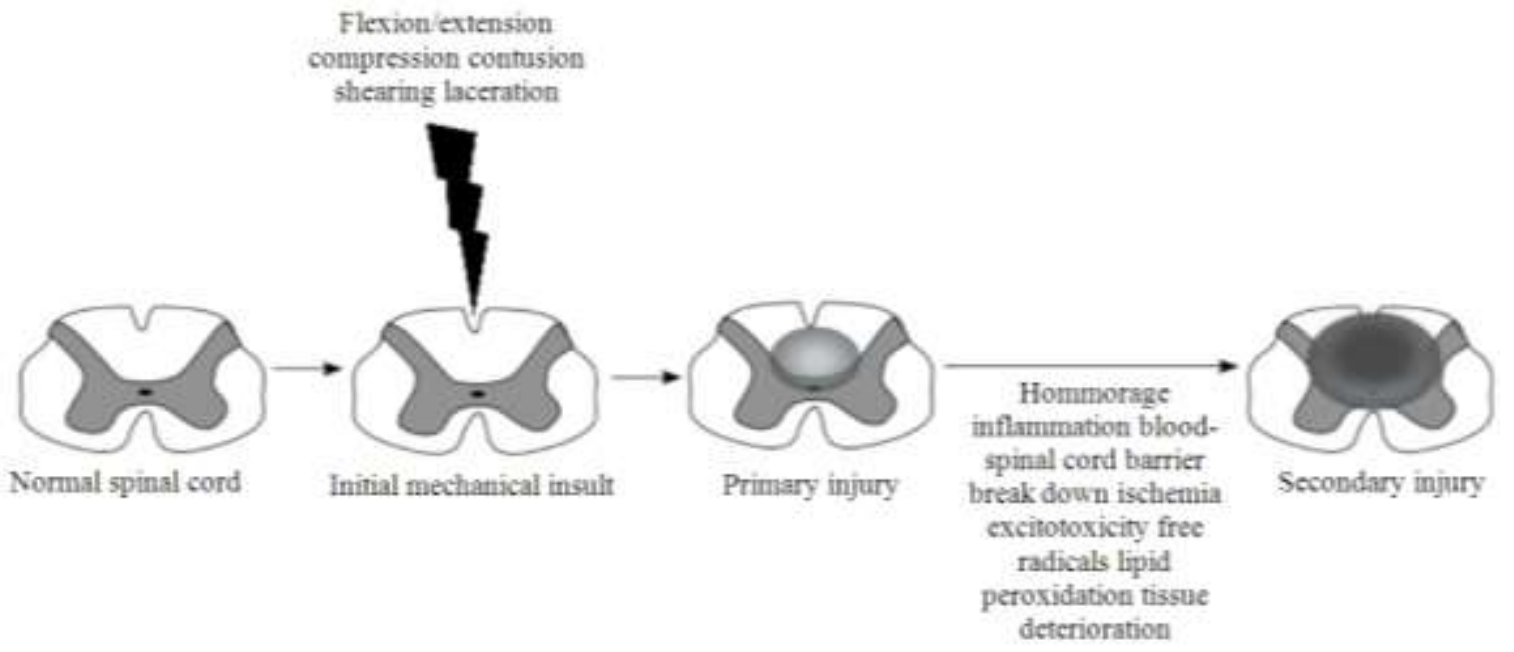

Fig. 1. Acute Spinal Cord Injury (SCI) involves both primary and secondary injuries. Schematic representation of SCI pathophysiology consisting of primary and secondary mechanisms of damage. After the initial mechanical insult, a collection of vascular, biochemical and cellular events occur that not only initiate a secondary set of injury cascades but also induce additional tissue loss and dysfunction that extends beyond the original trauma site<smiles>COc1ccc(C2CN[C@H](O)C2)cc1OC1CCCC1</smiles>

(A)

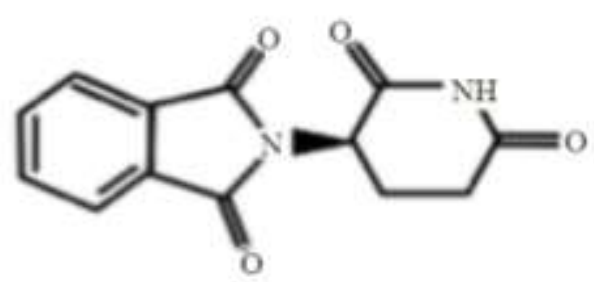

(D)<smiles>O=P(O)(O)C(Cl)(Cl)P(=O)(O)O</smiles>

(B)

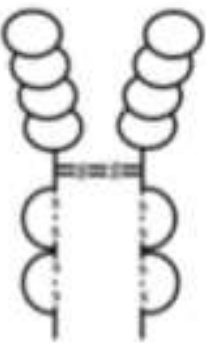

(C)<smiles>Cn1c(=O)c2[nH]cnc2n1C</smiles>

(E)

Fig. 2. Chemical structures of immune-based therapeutics discussed including: (A) Rolipram, (B) Liposomal Clodronate, (C) Etanercept, (D) Thalidomide and (E) Theophylline

$\mathrm{T}$ and $\mathrm{B}$ lymphocytes also infiltrate the injured mammalian spinal cord, although in fewer numbers and at later times post-injury than monocytes (Popovich et al., 1997; Sroga et al., 2003; Ankeny et al., 2006). The functional significance of $\mathrm{T}$ and $\mathrm{B}$ cells in the injured spinal cord remains a point of controversy (Popovich and Longbrake, 2008; Ankeny and Popovich, 2009).

The spatial extent of secondary injury events spreads both radially and longitudinally along the spinal cord in a rostral-to-caudal manner. The end result is cavitation of 
central gray matter along with partial or complete loss of adjacent white matter tracts (Tator, 1998; Norenberg et al., 2004). Cell death following SCI occurs by necrosis and apoptosis. While necrosis predominates immediately following the primary traumatic episode, delayed stages of subacute spinal cord pathology induce apoptosis predominantly of oligodendrocytes and to lesser extent neurons (Casha et al., 2001). Each event within the secondary injury represents an important therapeutic target for SCI. By focusing on immune-based therapies, injuries including severed and/or demyelinated axons, inflammatory cells and proinflammatory cytokines and glial scar components. Also, considering the multifaceted nature of secondary pathologic events attributed to SCI, drug cocktails with diverse modes of neuroprotection will likely be useful in preventing or limiting secondary injury progression.

Numerous studies examining the effects of several immunomodulatory drugs, including rolipram, thalidomide, liposomal clodronate, IL-10, etanercept, interferon- $\beta$, immunoglobulin $\mathrm{G}$, minocycline and Lipitor support the notion that immunomodulatory therapies after experimental SCI may be beneficial in promoting functional recovery (Iannotti et al., 2011; Beaumont et al., 2009; Koopmans et al., 2009; Whitaker et al., 2008; Pannu et al., 2007; Gok et al., 2007; Genovese et al., 2006; Stirling et al., 2004).

The purpose of this review is to focus on the therapeutic potential of the most abundant immune-based therapies in SCI e.g. rolipram, liposomal clodronate and TNF- $\alpha$ based therapy including etanercept, thalidomide and adenosine A1 receptor therapy (Fig. 2).

\subsection{Phosphodiesterase Inhibitors (Rolipram)}

The intensity and duration of the inflammatory response directly relates to the intracellular concentration of cAMP (Bruno et al., 2004), a second messenger that controls many cellular processes (Beavo and Brunton, 2002). Increased intracellular cAMP contributes to inhibition of proinflammatory cellular functions such as chemotaxis, degranulation, superoxide anion generation, release of IL-8 and phagocytosis in neutrophils (Ottonello et al., 1995; Rossi et al., 1998; Pryzwansky and Madden, 2003; Pearse et al., 2004). Furthermore, monocyte adhesion and migration are inhibited by high cAMP levels, as are phagocytosis and nitric oxide production in macrophages (Rossi et al., 1998; Zhu et al., 2001; Aronoff et al., 2005). Increased cAMP reduces adhesion molecule (CD11b/CD18/L-selectin) expression on leukocytes, leukocyte adhesion to other cells and disrupts chemokine induced chemotaxis (Harvath et al., 1991; Derian et al., 1995).
Rolipram is a well studied Phosphodiesterase type 4 (PDE4) inhibitor and has been shown to inhibit leukocyte functions, including leukotriene production by monocytes and to have anti-inflammatory effects in vivo that include inhibition of neutrophil migration (Griswold et al., 1993). These findings indirectly demonstrate a role for PDE4 in several functions of monocytes and neutrophils. Furthermore, the PDE4B subtype has been identified in activated microglia of the injured spinal cord (Whitaker et al., 2008). Targeted inhibition of the PDE4, is a potentially powerful tool (Houslay and Adams, 2003) as PDE4 inhibitors suppress the production of $\mathrm{TNF}-\alpha$, the generation of reactive oxides and the migration of neutrophils (Torphy, 1998; Giembycz, 2000). Rolipram has been shown to decrease the production of TNF- $\alpha \square$ in homogenates of the injured spinal cord and in activated human mononuclear cells (Semmler et al., 1993; Pearse et al., 2004).

Rolipram delivery in the first $72 \mathrm{~h}$ after SCI in rats has neuroprotective effects, sparing oligodendrocytes from death at $27 \mathrm{~h}$ post-injury, an effect that may have involved abrogation of local inflammation (Whitaker et al., 2008). Rolipram has been used also in combination with cellular transplant yielding cellular sparing and improved motor outcomes (Pearse et al., 2004; Koopmans et al., 2009; Beaumont et al., 2009; Bretzner et al., 2010). Moreover, Iannotti et al. (2011) mentioned the ability of rolipram in combination with liposomal-encapsulated clodronate to enhance myelinated tissue sparing and improve hindlimb functional recovery at 4 weeks postinjury. Additionally, histological assessment revealed substantial axonal sparing and/or sprouting from several brainstem motor nuclei and hindlimb motor cortex, a significant reduction in lesion volume $(51 \%)$ and lesion area at the injury epicenter $(45 \%)$ and a significant increase in the extent of myelinated tissue sparing (Iannotti et al., 2011). Together, these studies suggest a neuroprotective effect of the early administration of this PDE4 inhibitor.

Others have demonstrated the effectiveness of rolipram in promoting regeneration after spinal cord injury due to its effectiveness in blocking growth cone collapse (Nikulina et al., 2004; Pearse et al., 2004). Kajana and Goshgarian (2008) shown that rolipram can increase phrenic nerve output ipsilateral to an experimental C2 hemisection lesion. Additionally, intravenous rolipram restored respiratory-related activity to the phrenic nerve ipsilateral to the injury and significantly enhanced phrenic nerve inspiratory burst activity in both normal and $\mathrm{C} 2$ hemisected animals. These results provided evidence that PDE inhibitors can 
strengthen spared ineffective synaptic connections at the level of the phrenic nucleus and may enhance phrenic nerve output and restore respiratory related phrenic nerve function after high cervical SCI (Kajana and Goshgarian, 2008).

These findings emphasize the usefulness of PDE4 inhibitors in promoting axonal regeneration following experimental SCI, particularly in combination with cellular implants (Qiu et al., 2002; Nikulina et al., 2004; Pearse et al., 2004; Kajana and Goshgarian, 2008; Bretzner et al., 2010) and in exerting neuroprotective effects like cellular sparing, myelination, improving neurotransmission through the ventrolateral funiculus and functional recovery (Pearse et al., 2004; Whitaker et al., 2008; Beaumont et al., 2009; Iannotti et al., 2011).

Rolipram is a "readily-available" drug and its clinical efficacy has been assessed in the treatment of several disorders including depression, systemic lupus erythematosus, rheumatoid arthritis, asthma, chronic obstructive pulmonary disease and multiple sclerosis (Dyke and Montana, 2002). While recent clinical evaluation of rolipram has been hampered by side effects of nausea and vomiting, a new generation of PDE4 inhibitors with a less adverse side effect profile is under evaluation (Dastidar et al., 2009; Davis et al., 2009).

\subsection{Macrophage Depletion (Liposome- Encapsulated Clodronate)}

The effect of macrophage infiltration in SCI injury is highly controversial. Several studies have reported both beneficial and harmful effects of macrophages and/or microglia after injury (Prewitt et al., 1997; Rapalino et al., 1998; Fitch et al., 1999; Popovich et al., 1999; Schwartz et al., 1999; Bomstein et al., 2003; Yin et al., 2003; McPhail et al., 2004; Horn et al., 2008; Iannotti et al., 2011). Activated microglia and extravasated blood monocytes constitute the majority of inflammatory cells present at the site of a SCI (Blight, 1985; Dusart and Schwab, 1994; Popovich et al., 1996; Carlson et al., 1998). Whether these cells act in a coordinated fashion to resolve the injury site or whether they adopt distinct functional repertoires is unclear. However, the contribution and functional status of one macrophage subset relative to the other is likely to be influenced by several factors including: (i) the nature of the primary insult (e.g., transection, infection, blunt trauma, ischemia); (ii) interactions with resident and infiltrating cells; (iii) distance from the site of the injurious stimulus, related to blood-brain barrier damage and chemotactic gradients; and (iv) exposure to humoral factors or substrates of non-CNS origin (e.g., complement protein, peripheral nervous system components, or drugs). These variables will affect microglial/macrophage activation and whether secondary damage or repair occurs (Popovich et al., 1999).

After SCI, the onset of repair precedes hematogenous macrophage infiltration but not the activation of resident microglia. Therefore, interventions that alter the kinetics or nature of the inflammatory response to trauma might affect later stages of repair, including axon regeneration. Since the matrix that forms after injury is not sufficient to maintain axonal growth, it is possible that infiltrating macrophages antagonize the efforts of resident cells to repair the injury site. Fitch and Silver (1997) support the concept that the inefficient progression of endogenous repair and the formation of an axon restrictive growth environment are mediated by blood-brain barrier damage, acute infiltration of blood monocytes and the accumulation of inhibitory extracellular matrix molecules. Acute macrophage depletion limits chondroitin sulfate proteoglycan deposition and reduces the phagocytosis-coupled release of antibacterial agents (e.g., superoxide, hydrogen peroxide, hypochlorous acid), quinolinic acid, or proteolytic enzymes. These latter compounds, although innocuous in the regenerative tissues of the periphery, could cause inefficient repair, progressive necrosis/apoptosis and destruction of healthy tissues and neural/glial progenitors within the CNS (Popovich et al., 1999).

Clodronate is a first-generation bisphosphonate drug which, when encapsulated by liposomes, induces the selective apoptotic cell death of monocytes and phagocytic macrophages (Van Rooijen and Sanders, 1994; Selander et al., 1996). Horn et al. (2008) show that activated macrophages and microglia can induce longdistance retraction of dystrophic axons both in vitro and in vivo after dorsal spinal cord hemisection and that macrophage depletion with liposomal clodronate is capable of attenuating axonal "die-back" following dorsal column lesioning. Moreover, Iannotti et al. (2011) reported that an intra-peritoneal injection of liposomal clodronate immediately after injury and on days 1, 3 and 6 post-injury improved myelinated tissue sparing, reduced ED-1+ macrophage infiltration and enhanced locomotor recovery. Additional studies support the notion that depletion or neutralization of neutrophils and macrophages resulted in reduced lesion volume, increased neuronal survival and improved functional recovery (Giulian and Robertson, 1990; Blight, 1994; Rabchevsky and Streit, 1997; Popovich et al., 1999; Van Rooijen and Kesteren-Hendrikx, 2002; Gok et al., 2007; Iannotti et al., 2011). 
All of these recent studies strongly suggest that the activated macrophages infiltrating to the injury site act as a regenerative barrier and contradict earlier studies that have described the beneficial effects of macrophage transplants into the injured spinal cord (Rapalino et al., 1998; Bomstein et al., 2003). The dual nature of the effects of macrophages after SCI is complicated (Popovich and Longbrake, 2008) and suggests that the best approach for treatment following spinal cord injury may be to modify the state of macrophage activation rather than deplete the macrophages altogether (Blight, 1992; Jones et al., 2005; Hohlfeld et al., 2007).

\subsection{TNF- $\alpha$ Therapy}

The pathophysiology of spinal cord injury includes an initial mechanical injury that is followed by a cascade of secondary degenerative cellular and molecular processes. The secondary damage is initiated by considerable disruptions in blood supply, breakdown of the blood-spinal cord barrier, a significant release of inflammatory mediators, chemokines, cytokines and neurotoxins within the area; leading to further tissue deterioration (Tyor et al., 2002; Chi et al., 2008; Sharma, 2011). Amongst the proinflammatory cytokines expressed, expression of tumor necrosis factor-alpha (TNF- $\alpha$ ) has been identified as being rapidly upregulated at the lesion site after SCI (Wang et al., 1996; Streit et al., 1998; Bethea et al., 1999; Hayashi et al., 2000; Yan et al., 2001; Wang et al., 2002; Yune et al., 2003).

TNF- $\alpha$ influences immunity, inflammation, cell proliferation, differentiation and apoptosis and is found as either a transmembrane protein or soluble cytokine (Bayrakli et al., 2012). Within the CNS, TNF- $\alpha$ is generated by astrocytes, microglia and various neuronal populations (McCoy and Tansey, 2008; Caminero et al., 2011). Binding to either of the two distinct TNF receptors, TNFR1 and TNFR2, activates separate pathways that either elicits pro-inflammatory or apoptotic signaling or pro-inflammatory and survival signaling, respectively (Bayrakli et al., 2012). Both stress and injury induce the release of $\mathrm{TNF}-\alpha$ and additional cytokines (Ferguson et al., 2008).

Data has shown that $\mathrm{TNF}-\alpha$ protein levels are significantly increased within $1 \mathrm{~h}$ post-SCI and decline between 8 and $20 \mathrm{~h}$ after lesion production (Wang et al., 1996). Notably, TNF- $\alpha$ is released more rapidly when compared to other pro-inflammatory cytokines and essentially functions to initiate Wallerian degeneration, activate Schwann cells and assist with the recruitment of macrophage to the injury site (Stoll et al., 2002; Esposito and Cuzzocrea, 2011). Furthermore, it is thought that this initial acute phase of TNF- $\alpha$ activity at the lesion site plays a deleterious role in secondary injury (Wang et al., 1996; Brewer and Nolan, 2007; Chi et al., 2008).

Early studies specifically revealed that TNF- $\alpha$ enhances the permeability of endothelial cells, damages the blood brain barrier, causes apoptosis, activates astrocytes, contributes to glial scar formation, initiates glutamate mediated cellular death and induces the expression of iNOS and NF- $\alpha$ B (Selmaj et al., 1990; Schobitz et al., 1994; D'Souza et al., 1995; Sipe et al., 1996; Akassoglou et al., 1998; Bethea et al., 1999; Lee et al., 2000; Beattie et al., 2002; Wang et al., 2002; Hausmann, 2003; Brewer and Nolan, 2007). When examining tissue damage in chronically injured spinal cords, it was noted that TNF- $\alpha$ transgenic rats had enhanced tissue healing and a persistent baseline level of TNF- $\alpha$ in comparison to wild-type littermates (Chi et al., 2008). This chronic data, as well as other studies, suggest that TNF- $\alpha$ may be destructive in the acute phase of injury and beneficial during chronic stages of SCI (Bethea et al., 1999; Hausmann, 2003; Brewer and Nolan, 2007; Chi et al., 2008).

Because TNF- $\alpha$ acts as signal to trigger apoptosis in the spinal cord following injury, the neutralization of this neurodestructive factor at the most optimal time could be an essential tool to promote neuroprotection in the cord following trauma (Yune et al., 2003; Sharma, 2010). Ideally, a therapeutic approach would not only harness the benefits of early TNF- $\alpha$ inhibition but would also take advantage of the potential for contributions to functional recovery in chronic SCI conditions by maintaining optimal physiological levels.

\subsection{Etanercept}

Etanercept, a TNF- $\alpha$ antagonist, is a genetically engineered fusion protein that is comprised of the extracellular ligand-binding portion of TNFR2 fused to a portion of human IgG1 and functions as a decoy receptor that competitively binds TNF- $\alpha$ and TNF- $\alpha$ (Genovese et al., 2006; Kato et al., 2010; Caminero et al., 2011; Bayrakli et al., 2012). Overall, the primary therapeutic objective of TNF antagonist administration is to reduce excessive TNF from circulation and inflammation sites (Genovese et al., 2006). Because etanercept functions in vivo as a selective antagonist of TNF, it has been utilized as a treatment option for several inflammatory conditions, traumatic brain injury and neurodegenerative diseases.

The functional significance of etanercept therapy post-SCI has been specifically addressed in several 
studies and has revealed remarkable results. An early immunohistochemical and motor study reported that experimental animals treated with etanercept had reduced TNF- $\alpha$ expression, cell apoptosis, neutrophil infiltration and spinal cord damage and improved motor function (Genovese et al., 2006). Another investigation examining the outcomes of immediate etanercept therapy after a peripheral nerve injury revealed that experimental groups had a significant enhancement in axonal regeneration when compared to vehicle treated animals (Kato et al., 2010). A recent study examined the potential suppression of neuronal and oligodendroglial apoptosis by giving etanercept $1 \mathrm{~h}$ after thoracic SCI in rats. Data indicate that treated animals had reduced tissue damage associated with SCI, improved hindlimb locomotor function and myelin regeneration (Chen et al., 2011). The neuroelectrophysical effectiveness of entanercept was investigated under partial SCI conditions and results illustrated that the treated groups of animals had significant clinical and electrophysiological recovery that was not seen in controls (Bayrakli et al., 2012). Lastly, it was postulated that the significant motor recovery demonstrated in a patient suffering from an initial $\mathrm{T} 7$ complete paraplegia, who by chance received etanercept prior to the accident, was possible because of the considerable reduction in post-traumatic spinal cord inflammation (Dinomais et al., 2009; Tobinick, 2010).

Together, data from these studies strongly imply that etanercept treatment significantly lessens the degree of inflammation and tissue damage associated with SCI by directly reducing the expression of TNF- $\alpha$ and TNFR during the acute phase of injury. Future studies examining the outcomes of etanercept administration on motor recovery, regeneration and plasticity are essential to not only determine the optimal treatment window but to also take advantage of a promising therapy.

\subsection{Thalidomide}

An alternative pharmacological strategy utilized in the reduction of secondary tissue damage after SCI is to administer the glutamic acid derivative thalidomide. Thalidomide is a psychoactive drug that easily crosses the blood brain barrier and elicits an inhibitory effect on TNF- $\alpha$ in vitro and in vivo studies (Corral et al., 1999). Because it induces anti-inflammatory and immunomodulatory effects, thalidomide has recently been considered as a potential therapeutic in SCI and other diseases (Tseng et al., 1996; Esposito and Cuzzocrea, 2011).
In a mouse model of SCI, experimental animals treated with thalidomide had a significant decrease in the development of inflammation and secondary tissue damage (Genovese et al., 2008; Esposito and Cuzzocrea, 2011). Another study evaluated the effects of thalidomide on spinal cord ischemia and found that in experimental animals, treatment applied before ischemic insult reduced TNF- $\alpha$ levels and early phase ischemia/reperfusion injury of the spinal cord in rabbits (Lee et al., 2007). Lastly, by combining thalidomide with rolipram researches were able to demonstrate a significant attenuation of TNF- $\alpha$, enhanced sparing of white matter and improved motor function (Koopmans et al., 2009).

The overall decrease in secondary tissue degeneration suggests that utilizing a combinatorial therapy to reduce inflammation via different mechanisms compliment one another to elicit optimal results and may further improve functional output. Despite the modifications to TNF- $\alpha$ expression levels and secondary damage induced after SCI, additional studies examining the effectiveness and safety of thalidomide needs to be conducted.

\subsection{Adenosine A1 Therapy}

Following CNS trauma, a variety of inhibitory substances like adenosine and GABA are released; determining their exact contribution or prevention to secondary damage is of principal importance (Hagberg et al., 1987; Fern et al., 1994). In order to initiate downstream physiological events, adenosine must binds to one of its specific receptors, which are classified as A1, A2, A3 and A4 (Nantwi and Goshgarian, 2002). Adenosine is recognized as eliciting a tonic inhibitory effect on neuronal excitability (Gundlfinger et al., 2007) and by acting through its Gprotein coupled receptors can either inhibit (A1 and A3) or promote (A2a and A2b) cAMP synthesis (Dunwiddie and Masino, 2001; Kajana and Goshgarian, 2008). Specifically, activation of the A1 receptor elicits typical Gi/o mediated signaling events as well as proinflammatory effects on adhesion, migration and phagocytosis of neutrophils and monocytes/macrophages (Sawynok and Liu, 2003).

Early investigations sought to determine if adenosine release post-SCI offered a level of neuroprotection. By examining the concentrations of both adenosine and neurotoxic amino acids, data indicated that the release of endogenous adenosine was advantageous to minimizing tissue degeneration (McAdoo et al., 2000). While this study confirmed the idea that an increase in adenosine offered no neuroprotection, 
future investigations focused on the physiological outcome of adenosine antagonism after SCI.

The specific adenosine A1 and A2 receptor antagonist, theophylline, has been shown to pharmacologically induce plasticity by restoring respiratory muscle function following a spinal cord $\mathrm{C} 2$ hemisection (Nantwi et al., 1996; Nantwi and Goshgarian, 1998). In a multitude of species, adenosine receptors are localized to carotid bodies and modulate (depress) respiratory activity (McQueen and Ribeiro, 1983; Watt et al., 1987; Nikodijevic et al., 1991; James and Nantwi, 2006). That being said, application of an A1 receptor agonist has been shown to depress respiration (Eldridge et al., 1985; Wesberg et al., 1985), whereas inhibition of adenosine receptors is the foundation of the clinical aspect of theophylline treatment for respiratory deficiency (Richmond, 1949; Thithapandha et al., 1972; Nantwi and Goshgarian, 2002). Continuing with the $\mathrm{C} 2$ hemisection injury model, chronic theophylline treatment was found to elicit results that were similar to acute administration of the therapeutic and suggest that continuous use may not be optimal (Nantwi et al., 2003).

Taken together, these results suggest that obtaining a more thorough understanding of the molecular basis of the theophylline mediated recovery of respiratory function post-SCI would most likely guide the development of a comprehensive treatment strategy. While protective and destructive immunity response theories following SCI might appear contradictory, it is possible that both are partially correct. Specifically, some aspects of autoimmunity are beneficial and some are injurious. The ability to disable certain aspects of the immune function while keeping others intact is necessary to solve the complex functions of the immune system following neurotrauma. As new pharmacological tools are developed, the ability to examine these functions will improve. Moreover, the effects of combinational therapy will be pivotal to increase the ability to effectively modulate the immune system and maximize the regenerative potential of the CNS. For example, recent data has shown that immunomediators were capable of controlling the migration, proliferation, quiescence, cellfate choices and survival of neural stem cells and their progeny and may significantly contribute to the success of other therapeutic treatment strategies post-SCI (Gonzalez-Perez et al., 2012).

\section{CONCLUSION}

Spinal cord injury is first induced by a mechanical insult supporting secondary biochemical and physiological damage that ultimately promotes permanent loss of sensory and motor function (Pajoohesh-Ganji and Byrnes, 2011). The secondary damage initiates a series of degenerative events that results in further tissue destruction, massive cellular death, disrupted vasculature, increased permeability of the blood-spinal cord barrier, axonal demyelination, glial scar formation and neuroinflammation (Fehlings and Nguyen, 2010; Pajoohesh-Ganji and Byrnes, 2011; Jaerve and Muller, 2012). Because the secondary damage is so widespread, the prevention or a reduction in one or several of these secondary events post-SCI could potentially initiate spinal cord tissue repair and promote the overall improvement in functional outcomes.

Table 1. Comprehensive description of each pharmacological agent that includes the molecular formula, class of drug, mode of activity and downstream targets

\begin{tabular}{|c|c|c|c|c|}
\hline Agent & Molecular formula & Drug class & Target & Mode of action \\
\hline Rolipram & $\mathrm{C}_{16} \mathrm{H}_{21} \mathrm{NO}_{3}$ & PDE-4 inhinitor & $\begin{array}{l}\text { PDE-4 cAMP } \\
\text { phosphodiesterase }\end{array}$ & cAMP Accumulation \\
\hline Clodronate & $\mathrm{CH}_{4} \mathrm{Cl}_{2} \mathrm{O}_{6} \mathrm{P}_{2}$ & Bisphosphonate & $\begin{array}{l}\text { Macrophage } \\
\text { and microglia }\end{array}$ & $\begin{array}{l}\text { Apoptoses induction; } \\
\text { elimination of } \\
\text { macrophage }\end{array}$ \\
\hline Etanercept & $\begin{array}{l}\text { Recombinant dimmer of } \\
\text { human TNF-R proteins } \\
\text { bound to human IgG1 }\end{array}$ & $\begin{array}{l}\text { Tumor necrosis } \\
\text { factor blocker }\end{array}$ & TNF- $\alpha$ & binds to TNF- $\alpha$ and TNF $\beta$ \\
\hline Thalidomide & $\mathrm{C}_{13} \mathrm{H}_{10} \mathrm{~N}_{2} \mathrm{O}_{4}$ & Sedative & TNF- $\alpha$ & $\begin{array}{l}\text { Anti-inflammatory; } \\
\text { Immunomodulatory; } \\
\text { anti-angiogenic }\end{array}$ \\
\hline Theophylline & $\mathrm{C}_{7} \mathrm{H}_{8} \mathrm{~N}_{4} \mathrm{O}_{2}$ & Methylxanthine & $\begin{array}{l}\text { Adenosine A1 and } \\
\text { A2 Receports }\end{array}$ & PDE inhibitor \\
\hline
\end{tabular}


Indeed, focusing on any one of the cellular inflammatory responses as a therapy for SCI is of high importance. Extracellular molecules like cyto- and chemokines can be readily targeted by biological agents that demonstrate a high degree of specificity (Esposito and Cuzzocrea, 2011). For example, rolipram has been shown to prevent the reduction in cAMP levels after acute CNS injury as well as promote tissue protection, repair and functional recovery (Pearse et al., 2004; Atkins et al., 2006; Schaal et al., 2012). Additionally, a recent study described the benefits of utilizing a drugeluting microfibrous patch as means to deliver rolipram into the injured spinal cord and data indicated significant improvements in both functional and anatomical recovery (Downing et al., 2012). Clodronate has been shown to induce macrophage apoptosis (Monkkonen et al., 1994) and microglia elimination (Kumamaru et al., 2012) in vitro but the overall necessity of completely eradicating each is controversial at best. Focusing on the utilization of a TNF- $\alpha$ therapy that neutralizes injuryinduced apoptosis and inflammation may be one of the most crucial tools to promote neuroprotection in the cord following trauma (Yune et al., 2003; Sharma, 2010). Lastly, functional support has been addressed by treating SCI patients suffering from bradychardia with theophylline (Schulz-Stubner, 2005).

While the above pharmacological agents offer various levels of neuroprotection (Table 1), there are disadvantages associated with each therapy. Therefore, it is becoming increasingly clear that a prudent process for therapy design is not only required but that establishing the line between elimination and reduction of secondary molecules is critical. Ideally, this will involve thoroughly investigating and harnessing the benefits of combinatorial therapies, optimization of the dosage and delivery mode and establishment of the best therapeutic window so that clinical feasibility can be examined (Rabchevsky et al., 2011; Schaal et al., 2012).

\section{REFERENCES}

Akassoglou, K., J. Bauer, G. Kassiotis, M. Pasparakis and H. Lassmann et al., 1998. Oligodendrocyte apoptosis and primary demyelination induced by local TNF/p55TNF receptor signaling in the central nervous system of transgenic mice: Models for multiple sclerosis with primary oligodendrogliopathy. Am. J. Pathol., 153: 801-813. DOI: $10.1016 / \mathrm{S} 0002-9440(10) 65622-2$
Ankeny, D.P. and P.G. Popovich, 2009. Mechanisms and implications of adaptive immune responses after traumatic spinal cord injury. Neuroscience, 158: 1112-1121. DOI: 10.1016/j.neuroscience.2008.07.001

Ankeny, D.P., K.M. Lucin, V.M. Sanders, V.M. McGaughy and P.G. Popovich, 2006. Spinal cord injury triggers systemic autoimmunity: Evidence for chronic B lymphocyte activation and lupus-like autoantibody synthesis. J. Neurochem., 99: 10731087. DOI: $10.1111 / \mathrm{j} .1471-4159.2006 .04147 . x$

Aronoff, D.M., C. Canetti, C.H. Serezani, M. Luo and M. Peters-Golden, 2005. Cutting edge: Macrophage inhibition by cyclic AMP (cAMP): Differential roles of protein kinase A and exchange protein directly activated by cAMP-1. J. Immunol., 174: 595-599. PMID: 15634874

Atkins, C.M., S. Chen, O.F. Alonso, W.D. Dietrich and B.R. Hu, 2006. Activation of calcium/calmodulindependent protein kinases after traumatic brain injury. J. Cereb. Blood. Flow Metab., 26: 15071518. PMID: 16570077

Bayrakli, F., H. Balaban, U. Ozum, C. Duger and S. Topaktas et al., 2012. Etanercept treatment enhances clinical and neuroelectrophysiological recovery in partial spinal cord injury. Eur. Spine J., 21: 25882593. DOI: $10.1007 / \mathrm{s} 00586-012-2319-7$

Beattie, M.S., G.E. Hermann, R.C. Rogers and J.C. Bresnahan, 2002. Cell death in models of spinal cord injury. Prog. Brain Res., 137: 37-47. DOI: 10.1016/S0079-6123(02)37006-7

Beaumont, E., C.M. Whitaker, D.A. Burke, M. Hetman and S.M. Onifer, 2009. Effects of rolipram on adult rat oligodendrocytes and functional recovery after contusive cervical spinal cord injury. Neuroscience, 163: 985-990. DOI: 10.1016/j.neuroscience.2009.07.039

Beavo, J.A. and L.L. Brunton, 2002. Cyclic nucleotide research -- still expanding after half a century. Nat. Rev. Mol. Cell Biol., 3: 710-718. PMID: 12209131

Bethea, J.R., H. Nagashima, M.C. Acosta, C. Briceno and F. Gomez et al., 1999. Systemically administered interleukin-10 reduces tumor necrosis factor-alpha production and significantly improves functional recovery following traumatic spinal cord injury in rats. J. Neurotrauma, 16: 851-863. PMID: 10547095

Blight, A.R., 1985. Delayed demyelination and macrophage invasion: A candidate for secondary cell damage in spinal cord injury. Cent Nerv. Syst. Trauma, 2: 299-315. PMID: 3836014 
Blight, A.R., 1992. Macrophages and inflammatory damage in spinal cord injury. J. Neurotrauma, 9: S83-91. PMID: 1588634

Blight, A.R., 1994. Effects of silica on the outcome from experimental spinal cord injury: Implication of macrophages in secondary tissue damage. Neuroscience, 60: 263-273. DOI: 10.1016/03064522(94)90220-8

Bomstein, Y., J.B. Marder, K. Vitner, I. Smirnov and G. Lisaey et al., 2003. Features of skin-coincubated macrophages that promote recovery from spinal cord injury. J. Neuroimmunol., 142: 10-16. DOI: 10.1016/S0165-5728(03)00260-1

Bretzner, F., J.R. Plemel, J. Liu, M. Richter and A.J. Roskams et al., 2010. Combination of olfactory ensheathing cells with local versus systemic cAMP treatment after a cervical rubrospinal tract injury. J. Neurosci. Res., 88: 2833-2846. PMID: 20568293

Brewer, K.L. and T.A. Nolan, 2007. Spinal and supraspinal changes in tumor necrosis factor-alpha expression following excitotoxic spinal cord injury. J. Mol. Neurosci., 31: 13-21. PMID: 17416966

Bruno, O., C. Brullo, N. Arduino, S. Schenone and A. Ranise et al., 2004. Synthesis and biological evaluation of neutrophilic inflammation inhibitors. Farmaco, 59: 223-235. PMID: 14987986

Bunge, R.P., W.R. Puckett, J.L. Becerra, A. Marcillo and R.M. Quencer, 1993. Observations on the pathology of human spinal cord injury. A review and classification of 22 new cases with details from a case of chronic cord compression with extensive focal demyelination. Adv. Neurol., 59: 75-89. PMID: 8420126

Caminero, A., M. Comabella and X. Montalban, 2011. Tumor necrosis factor alpha (TNF-alpha), anti-TNFalpha and demyelination revisited: An ongoing story. J. Neuroimmunol., 234: 1-6. PMID: 21474190

Carlson, S.L., M.E. Parrish, J.E. Springer, K. Doty and L. Dossett, 1998. Acute inflammatory response in spinal cord following impact injury. Exp. Neurol., 151: 77-88. PMID: 9582256

Casha, S., W.R. Yu and M.G. Fehlings, 2001. Oligodendroglial apoptosis occurs along degenerating axons and is associated with FAS and p75 expression following spinal cord injury in the rat. Neurosciencem, 103: 203-218. DOI: 10.1016/S0306-4522(00)00538-8

Chang, H.T., 2007. Subacute human spinal cord contusion: Few lymphocytes and many macrophages. Spinal Cord, 45: 174-182. PMID: 16505827
Chen, K.B., K. Uchida, H. Nakajima, T. Yayama and T. Hirai et al., 2011. Tumor necrosis factor- $\alpha$ antagonist reduces apoptosis of neurons and oligodendroglia in rat spinal cord injury. Spine (Phila Pa 1976), 36: 1350-1358. PMID: 21224756

Chi, L.Y., J. Yu, H. Zhu, X.G. Li and S.G. Zhu et al., 2008. The dual role of tumor necrosis factor-alpha in the pathophysiology of spinal cord injury. Neurosci. Lett., 438: 174-179. DOI: 10.1016/j.neulet.2008.04.043

Corral, L.G., P.A. Haslett, G.W. Muller, R. Chen and L.M. Wong et al., 1999. Differential cytokine modulation and $\mathrm{T}$ cell activation by two distinct classes of thalidomide analogues that are potent inhibitors of TNF-alpha. J. Immunol., 163: 380-386. PMID: 10384139

D’Souza, S., K. Alinauskas, E. McCrea, C. Goodyer and J.P. Antel, 1995. Differential susceptibility of human CNS-derived cell populations to TNFdependent and independent immune-mediated injury. J. Neurosci., 15: 7293-7300. PMID: 7472483

Dastidar, S.G., A. Ray, R. Shirumalla, D. Rajagopal and S. Chaudhary et al., 2009. Pharmacology of a novel, orally active PDE4 inhibitor. Pharmacology, 83: 275-286. PMID: 19321962

Davis, T.G., J.J. Peterson, J.P. Kou, E.A. CapperSpudich and D. Ball et al., 2009. The identification of a novel phosphodiesterase 4 inhibitor, 1-ethyl-5\{5-[(4-methyl-1-piperazinyl)methyl]-1,3,4oxadiazol-2-yl \}-N-(tetrahydro-2H-pyran-4-yl)-1Hpyrazolo[3,4-b]pyridin-4-amine (EPPA-1), with improved therapeutic index using pica feeding in. J. Pharmacol. Exp. Ther., 330: 922-931. PMID: 19498103

Derian, C.K., R.J. Santulli, P.E. Rao, H.F. Solomon and J.A. Barrett, 1995. Inhibition of chemotactic peptide-induced neutrophil adhesion to vascular endothelium by cAMP modulators. J. Immunol., 154: 308-317. PMID: 7995950

Dinomais, M., L. Stana, G. Egon, I. Richard and P. Menei, 2009. Significant recovery of motor function in a patient with complete $\mathrm{T} 7$ paraplegia receiving etanercept. J. Rehab. Med., 41: 286-288. DOI: 10.2340/16501977-0329

Downing, T.L., A. Wang, Z.Q. Yan, Y. Nout and A.L. Lee et al., 2012. Drug-eluting microfibrous patches for the local delivery of rolipram in spinal cord repair. J. Control Release, 161: 910-917. PMID: 22634093 
Dunwiddie, T.V. and S.A. Masino, 2001. The role and regulation of adenosine in the central nervous system. Annu. Rev. Neurosci., 24: 31-55. PMID: 11283304

Dusart, I. and M.E. Schwab, 1994. Secondary cell death and the inflammatory reaction after dorsal hemisection of the rat spinal cord. Eur. J. Neurosci., 6: 712-724. PMID: 8075816

Dyke, H.J. and J.G. Montana, 2002. Update on the therapeutic potential of PDE4 inhibitors. Exp. Opin. Invest. Drugs, 11: 1-13. PMID: 11772317

Eldridge, F.L., D.E. Millhorn and J.P. Kiley, 1985. Antagonism by theophylline of respiratory inhibition induced by adenosine. J. Applied Physiol., 59: 14281433. PMID: 4066573

Esposito, E. and S. Cuzzocrea, 2011. Anti-TNF therapy in the injured spinal cord. Trends Pharmacol. Sci., 32: 107-115. PMID: 21185611

Fehlings, M.G. and D.H. Nguyen, 2010. Immunoglobulin G: A potential treatment to attenuate neuroinflammation following spinal cord injury. J. Clin. Immunol., 30: S109-S112. DOI: 10.1007/s10875-010-9404-7

Ferguson, A.R., R.N. Christensen, J.C. Gensel, B.A. Miller and F. Sun et al., 2008. Cell death after spinal cord injury is exacerbated by rapid TNF alphainduced trafficking of GluR2-lacking AMPARs to the plasma membrane. J. Neurosci., 28: 1139111400. DOI: 10.1523/JNEUROSCI.3708-08.2008

Fern, R., S.G. Waxman and B.R. Ransom, 1994. Modulation of anoxic injury in CNS white matter by adenosine and interaction between adenosine and GABA. J. Neurophysiol., 72: 2609-2616. PMID: 7897478

Fitch, M.T. and J. Silver, 1997. Activated macrophages and the blood-brain barrier: Inflammation after CNS injury leads to increases in putative inhibitory molecules. Exp. Neurol., 148: 587-603. PMID: 9417835

Fitch, M.T., C. Doller, C.K. Combs, G.E. Landreth and J. Silver, 1999. Cellular and molecular mechanisms of glial scarring and progressive cavitation: In vivo and in vitro analysis of inflammation-induced secondary injury after CNS trauma. J. Neurosci., 19: 8182-8198. PMID: 10493720

Fleming, J.C., M.D. Norenberg, D.A. Ramsay, G.A. Dekaban and A.E. Marcillo et al., 2006. The cellular inflammatory response in human spinal cords after injury. Brain, 129: 3249-3269. PMID: 17071951
Genovese, T., E. Mazzon, C. Crisafulli, R. Di Paola and C. Muia et al., 2006. Immunomodulatory effects of etanercept in an experimental model of spinal cord injury. J. Pharmacol. Exp. Ther., 316: 1006-1016. PMID: 16303916

Genovese, T., E. Mazzon, E. Esposito, R. Di Paola and R. Caminiti et al., 2008. Effect of thalidomide on signal transduction pathways and secondary damage in experimental spinal cord trauma. Shock, 30: 231240. PMID: 18197140

Giembycz, M.A., 2000. Phosphodiesterase 4 inhibitors and the treatment of asthma: Where are we now and where do we go from here. Drugs, 59: 193-212. PMID: 10730545

Giulian, D. and C. Robertson, 1990. Inhibition of mononuclear phagocytes reduces ischemic injury in the spinal cord. Ann. Neurol., 27: 33-42. PMID: 2301926

Gok, B., O. Okutan, E. Beskonakli, S. Palaoglu and H. Erdamar et al., 2007. Effect of immunomodulation with human interferon-beta on early functional recovery from experimental spinal cord injury. Spine (Phila $\mathrm{Pa}$ 1976), 32: 873-880. PMID: 17426631

Gonzalez-Perez, O., F. Gutierrez-Fernandez, V. LopezVirgen, J. Collas-Aguilar and Quinones-Hinojosa et al., 2012. Immunological regulation of neurogenic niches in the adult brain. Neuroscience, 226: 270281. PMID: 22986164

Gris, D., D.R. Marsh, M.A. Oatway, Y. Chen and E.F. Hamilton et al., 2004. Transient blockade of the CD11d/CD18 integrin reduces secondary damage after spinal cord injury, improving sensory, autonomic and motor function. J. Neurosci., 24: 4043-4051. PMID: 15102919

Griswold, D.E., E.F. Webb, J. Breton, J.R. White and P.J. Marshall et al., 1993. Effect of selective phosphodiesterase type IV inhibitor, rolipram, on fluid and cellular phases of inflammatory response. Inflammation, 17: 333-344. PMID: 7687237

Gundlfinger, A., J. Bischofberger, F.W. Johenning, M. Torvinen and D. Schmitz et al., 2007. Adenosine modulates transmission at the hippocampal mossy fibre synapse via direct inhibition of presynaptic calcium channels. J. Physiol., 582: 263-277. PMID: 17478533

Hagberg, H., P. Andersson, J. Lacarewicz, I. Jacobson and S. Butcher et al., 1987. Extracellular adenosine, inosine, hypoxanthine and xanthine in relation to tissue nucleotides and purines in rat striatum during transient ischemia. J. Neurochem., 49: 227-231. PMID: 3585332 
Harvath, L., J.D. Robbins, A.A. Russell and K.B. Seamon, 1991. cAMP and human neutrophil chemotaxis. Elevation of cAMP differentially affects chemotactic responsiveness. J. Immunol., 146: 224-232. PMID: 1701793

Hausmann, O.N., 2003. Post-traumatic inflammation following spinal cord injury. Spinal Cord, 41: 369378. PMID: 12815368

Hayashi, M., T. Ueyama, K. Nemoto, T. Tamaki and E. Senba, 2000. Sequential mRNA expression for immediate early genes, cytokines and neurotrophins in spinal cord injury. J. Neurotrauma, 17: 203-218. PMID: 10757326

Hohlfeld, R., M. Kerschensteiner and E. Meinl, 2007. Dual role of inflammation in CNS disease. Neurology, 68: S58-S63. PMID: 17548571

Horn, K.P., S.A. Busch, A.L. Hawthorne, N.V. Rooijen and J. Silver, 2008. Another barrier to regeneration in the CNS: Activated macrophages induce extensive retraction of dystrophic axons through direct physical interactions. J. Neurosci., 28: 93309341. PMID: 18799667

Houslay, M.D. and D.R. Adams, 2003. PDE4 cAMP phosphodiesterases: Modular enzymes that orchestrate signalling cross-talk, desensitization and compartmentalization. Biochem. J., 370: 1-18. PMID: 12444918

Iannotti, C.A., M. Clark, K.P. Horn, N.V. Rooijen, J. Silver and M.P. Steinmetz, 2011. A combination immunomodulatory treatment promotes neuroprotection and locomotor recovery after contusion SCI. Exp. Neurol., 230: 3-15. PMID: 20338167

Jacobs, W.B. and M.G. Fehlings, 2003. The molecular basis of neural regeneration. Neurosurgery, 53: 943948. PMID: 14519226

Jaerve, A. and H.W. Muller, 2012. Chemokines in CNS injury and repair. Cell Tissue Res., 349: 229-248. PMID: 22700007

James, E. and K.D. Nantwi, 2006. Involvement of peripheral adenosine A2 receptors in adenosine A1 receptor-mediated recovery of respiratory motor function after upper cervical spinal cord hemisection. J. Spinal Cord Med., 29: 57-66. PMID: 16572566

Jones, T.B., E.E. McDaniel and P.G. Popovich, 2005. Inflammatory-mediated injury and repair in the traumatically injured spinal cord. Curr. Pharm. Des., 11: 1223-1236. PMID: 15853679
Kajana, S. and H.G. Goshgarian, 2008. Administration of phosphodiesterase inhibitors and an adenosine A1 receptor antagonist induces phrenic nerve recovery in high cervical spinal cord injured rats. Exp. Neurol., 210: 671-680. PMID: 18289533

Kato, K., H. Liu, S. Kikuchi, R.R. Myers and V.I. Shubayev, 2010. Immediate anti-tumor necrosis factor-alpha (etanercept) therapy enhances axonal regeneration after sciatic nerve crush. J. Neurosci. Res., 88: 360-368. PMID: 19746434

Keane, R.W., A.R. Davis and W.D. Dietrich, 2006. Inflammatory and apoptotic signaling after spinal cord injury. J Neurotrauma, 23: 335-344. PMID: 16629620

Kigerl, K.A., V.M. McGaughy and P.G. Popovich, 2006. Comparative analysis of lesion development and intraspinal inflammation in four strains of mice following spinal contusion injury. J Comp. Neurol., 494: 578-594. PMID: 16374800

Koopmans, G.C., R. Deumens, A. Buss, L. Geoghegan and A.M. Myint et al., 2009. Acute rolipram/thalidomide treatment improves tissue sparing and locomotion after experimental spinal cord injury. Exp. Neurol., 216: 490-498. PMID: 19320007

Kumamaru, H., H. Saiwai, K. Kobayakawa, K. Kubota and N.V. Rooijen et al., 2012. Liposomal clodronate selectively eliminates microglia from primary astrocyte cultures. J. Neuroinflammation, 9: 116. PMID: 22651847

Lee, C.J., K.W. Kim, H.M. Lee, F.S. Nahm and Y.J. Lim et al., 2007. The effect of thalidomide on spinal cord ischemia/reperfusion injury in a rabbit model. Spinal Cord, 45: 149-157. PMID: 16568139

Lee, Y.B., T.Y. Yune, S.Y. Baik, Y.H. Shin and S. Du et al., 2000. Role of tumor necrosis factor-alpha in neuronal and glial apoptosis after spinal cord injury. Exp. Neurol., 166: 190-195. PMID: 11031095

McAdoo, B.G., L.F. Pratson and D.L. Orange, 2000. Submarine landslide geomorphology, US continental slope. Marine Geol., 169: 103-136.

McCoy, M.K. and M.G. Tansey, 2008. TNF signaling inhibition in the CNS: Implications for normal brain function and neurodegenerative disease. $J$. Neuroinflammation, 5: 45-45. PMID: 18925972

McPhail, L.T., D.P. Stirling, W. Tetzlaff, J.M. Kwiecien and M.S. Ramer, 2004. The contribution of activated phagocytes and myelin degeneration to axonal retraction/dieback following spinal cord injury. Eur. J. Neurosci., 20: 1984-1994. PMID: 15450077 
McQueen, D.S. and J.A. Ribeiro, 1983. On the specificity and type of receptor involved in carotid body chemoreceptor activation by adenosine in the cat. Br. J. Pharmacol., 80: 347-354. PMID: 6317132

Monkkonen, J., M. Taskinen, S.O. Auriola and A. Urtti, 1994. Growth inhibition of macrophage-like and other cell types by liposome-encapsulated, calciumbound and free bisphosphonates in vitro. J. Drug Target, 2: 299-308. PMID: 7858955

Nantwi, K.D. and H.G. Goshgarian, 1998. Effects of chronic systemic theophylline injections on recovery of hemidiaphragmatic function after cervical spinal cord injury in adult rats. Brain Res., 789: 126-129. DOI: 10.1016/S0006-8993(98)00024-9

Nantwi, K.D. and H.G. Goshgarian, 2002. Actions of specific adenosine receptor $\mathrm{A} 1$ and $\mathrm{A} 2$ agonists and antagonists in recovery of phrenic motor output following upper cervical spinal cord injury in adult rats. Clin. Exp. Pharmacol. Physiol., 29: 915-923. PMID: 12207572

Nantwi, K.D., A. El-Bohy and H.G. Goshgarian, 1996. Actions of systemic theophylline on hemidiaphragmatic recovery in rats following cervical spinal cord hemisection. Exp. Neurol., 140: 53-59. PMID: 8682179

Nantwi, K.D., G.J. Basura and H.G. Goshgarian, 2003. Effects of long-term theophylline exposure on recovery of respiratory function and expression of adenosine A1 mRNA in cervical spinal cord hemisected adult rats. Exp. Neurol., 182: 232-239. DOI: 10.1016/S0014-4886(03)00109-2

Nathan, C., 2006. Neutrophils and immunity: Challenges and opportunities. Nat. Rev. Immunol., 6: 173-182. PMID: 16498448

Nguyen, H.X., M.D. Galvan and A.J. Anderson, 2008. Characterization of early and terminal complement proteins associated with polymorphonuclear leukocytes in vitro and in vivo after spinal cord injury. J. Neuroinflammation, 5: 26-26. PMID: 18578885

Nikodijevic, O., R. Sarges, J.W. Daly and K.A. Jacobson, 1991. Behavioral effects of A1- and A2selective adenosine agonists and antagonists: Evidence for synergism and antagonism. J. Pharmacol. Exp. Ther., 259: 286-294. PMID: 1920121

Nikulina, E., J.L. Tidwell, H.N. Dai, B.S. Bregman and M.T. Filbin, 2004. The phosphodiesterase inhibitor rolipram delivered after a spinal cord lesion promotes axonal regeneration and functional recovery. Proc. Natl. Acad. Sci. USA., 101: 87868790. PMID: 15173585
Noble, L.J., F. Donovan, T. Igarashi, S. Goussev and Z. Werb, 2002. Matrix metalloproteinases limit functional recovery after spinal cord injury by modulation of early vascular events. J. Neurosci., 22: 7526-7535. PMID: 12196576

Norenberg, M.D., J. Smith and A. Marcillo, 2004. The pathology of human spinal cord injury: Defining the problems. J. Neurotrauma, 21: 429-440. PMID: 15115592

Ottonello, L., M.P. Morone, P. Dapino and F. Dallegri, 1995. Cyclic AMP-elevating agents down-regulate the oxidative burst induced by GranulocyteMacrophage Colony-Stimulating Factor (GM-CSF) in adherent neutrophils. Clin. Exp. Immunol., 101: 502-506. PMID: 7664497

Pajoohesh-Ganji, A. and K.R. Byrnes, 2011. Novel neuroinflammatory targets in the chronically injured spinal cord. Neurotherapeutics, 8: 195-205. PMID: 21394541

Pannu, R., D.K. Christie, E. Barbosa, I. Singh and A.K. Singh, 2007. Post-trauma Lipitor treatment prevents endothelial dysfunction, facilitates neuroprotection and promotes locomotor recovery following spinal cord injury. J. Neurochem., 101: 182-200. PMID: 17217414

Pearse, D.D., F.C. Pereira, A.E. Marcillo, M.L. Bates and Y.A. Berrocal et al., 2004. cAMP and Schwann cells promote axonal growth and functional recovery after spinal cord injury. Nat. Med., 10: 610-616. PMID: 15156204

Popovich, P.G. and E.E. Longbrake, 2008. Can the immune system be harnessed to repair the CNS. Nat. Rev. Neurosci., 9: 481-493. PMID: 18490917

Popovich, P.G., N.V. Rooijen, W.F. Hickey, G. Preidis and V. McGaughy, 2003. Hematogenous macrophages express CD8 and distribute to regions of lesion cavitation after spinal cord injury. Exp. Neurol., 182: 275-287. DOI: 10.1016/S00144886(03)00120-1

Popovich, P.G., P. Wei and B.T. Stokes, 1997. Cellular inflammatory response after spinal cord injury in Sprague-Dawley and Lewis rats. J. Comp. Neurol., 377: 443-464. PMID: 8989657

Popovich, P.G., P.J. Horner, B.B. Mullin and B.T. Stokes, 1996. A quantitative spatial analysis of the blood-spinal cord barrier. I. Permeability changes after experimental spinal contusion injury. Exp. Neurol., 142: 258-275. PMID: 8934558

Popovich, P.G., Z. Guan, P. Wei, I. Huitinga and N.V. Rooijen et al., 1999. Depletion of hematogenous macrophages promotes partial hindlimb recovery and neuroanatomical repair after experimental spinal cord injury. Exp. Neurol., 158: 351-365. PMID: 10415142 
Prewitt, C.M., I.R. Niesman, C.J. Kane and J.D. Houle, 1997. Activated macrophage/microglial cells can promote the regeneration of sensory axons into the injured spinal cord. Exp. Neurol., 148: 433-443. PMID: 9417823

Pryzwansky, K.B. and V.J. Madden, 2003. Type 4A cAMP-specific phosphodiesterase is stored in granules of human neutrophils and eosinophils. Cell Tissue Res., 312: 301-311. PMID: 12764607

Qiu, J., D. Cai, H. Dai, M. McAtee and P.N. Hoffman et al., 2002. Spinal axon regeneration induced by elevation of cyclic AMP. Neuron, 34: 895-903. DOI: 10.1016/S0896-6273(02)00730-4

Rabchevsky, A.G. and W.J. Streit, 1997. Grafting of cultured microglial cells into the lesioned spinal cord of adult rats enhances neurite outgrowth. J. Neurosci. Res., 47: 34-48. PMID: 8981236

Rabchevsky, A.G., S.P. Patel and J.E. Springer, 2011. Pharmacological interventions for spinal cord injury: Where do we stand? How might we step forward. Pharmacol. Ther., 132: 15-29. PMID: 21605594

Rapalino, O., O. Lazarov-Spiegler, E. Agranov, G.J. Velan and E. Yoles et al., 1998. Implantation of stimulated homologous macrophages results in partial recovery of paraplegic rats. Nat. Med., 4: 814-821. PMID: 9662373

Richmond, G.H., 1949. Action of caffeine and aminophylline as respiratory stimulants in man. $\mathbf{J}$. Applied Physiol., 2: 16-23. PMID: 18133123

Rossi, A.G., J.C. McCutcheon, N. Roy, E.R. Chilvers and C. Haslett et al., 1998. Regulation of macrophage phagocytosis of apoptotic cells by cAMP. J. Immunol., 160: 3562-3568. PMID: 9531319

Savill, J.S., A.H. Wyllie, J.E. Henson, M.J. Walport and P.M. Henson et al., 1989. Macrophage phagocytosis of aging neutrophils in inflammation. Programmed cell death in the neutrophil leads to its recognition by macrophages. J. Clin. Invest., 83: 865-875. PMID: 2921324

Sawynok, J. and X.J. Liu, 2003. Adenosine in the spinal cord and periphery: Release and regulation of pain. Prog. Neurobiol., 69: 313-340. DOI: 10.1016/S0301-0082(03)00050-9

Schaal, S.M., M.S. Garg, M. Ghosh, L. Lovera and M. Lopez et al., 2012. The therapeutic profile of rolipram, PDE target and mechanism of action as a neuroprotectant following spinal cord injury. PLoS One, 7: e43634-e43634. DOI: PMID: 23028463

Schobitz, B., E.R. De Kloet and F. Holsboer, 1994. Gene expression and function of interleukin 1, interleukin 6 and tumor necrosis factor in the brain. Prog. Neurobiol., 44: 397-432. DOI: 10.1016/03010082(94)90034-5

Scholz, M., J. Cinatl, M. Schadel-Hopfner and J. Windolf, 2007. Neutrophils and the blood-brain barrier dysfunction after trauma. Med. Res. Rev., 27: 401-416. PMID: 16758487
Schulz-Stubner, S., 2005. The Use of small-dose theophylline for the treatment of bradycardia in patients with spinal cord injury. Anesthesia Analgesia, 101: 1809-1811. PMID: 16301263

Schwab, M.E. and D. Bartholdi, 1996. Degeneration and regeneration of axons in the lesioned spinal cord. Physiol. Rev., 76: 319-370. PMID: 8618960

Schwartz, M., O. Lazarov-Spiegler, O. Rapalino, I. Agranov and G. Velan et al., 1999. Potential repair of rat spinal cord injuries using stimulated homologous macrophages. Neurosurgery, 44: 10411045. PMID: 10232537

Sekhon, L.H. and M.G. Fehlings, 2001. Epidemiology, demographics and pathophysiology of acute spinal cord injury. Spine, 26: S2-S12. PMID: 11805601

Selander, K.S., J. Monkkonen, E.K. Karhukorpi, P. Harkonen and R. Hannuniemi et al., 1996. Characteristics of clodronate-induced apoptosis in osteoclasts and macrophages. Mol. Pharmacol., 50: 1127-1138. PMID: 8913344

Selmaj, K.W., M. Farooq, W.T. Norton, C.S. Raine and C.F. Brosnan, 1990. Proliferation of astrocytes in vitro in response to cytokines. A primary role for tumor necrosis factor. J. Immunol., 144: 129-135. PMID: 2104886

Semmler, J., H. Wachtel and S. Endres, 1993. The specific type IV phosphodiesterase inhibitor rolipram suppresses tumor necrosis factor-alpha production by human mononuclear cells. Int. J. Immunopharmacol., 15: 409-413. DOI: 10.1016/0192-0561(93)90052-Z

Sharma, H.S., 2010. A combination of tumor necrosis factor-alpha and neuronal nitric oxide synthase antibodies applied topically over the traumatized spinal cord enhances neuroprotection and functional recovery in the rat. Ann. N Y Acad. Sci., 175-185. PMID: 20633123

Sharma, H.S., 2011. Early microvascular reactions and blood-spinal cord barrier disruption are instrumental in pathophysiology of spinal cord injury and repair: Novel therapeutic strategies including nanowired drug delivery to enhance neuroprotection. J. Neural Transm, 118: 155-176. PMID: 21161717

Sipe, K.J., D. Srisawasdi, R. Dantzer, K.W. Kelley and J.A. Weyhenmeyer, 1996. An endogenous $55 \mathrm{kDa}$ TNF receptor mediates cell death in a neural cell line. Brain Res. Mol. Brain Res., 38: 222-232. DOI: 10.1016/0169-328X(95)00310-O

Sroga, J.M., T.B. Jones, K.A. Kigerl, V.M. McGaughy and P.G. Popovich, 2003. Rats and mice exhibit distinct inflammatory reactions after spinal cord injury. J. Comp. Neurol., 462: 223-240. PMID: 12794745 
Stirling, D. P. and V.W. Yong, 2008. Dynamics of the inflammatory response after murine spinal cord injury revealed by flow cytometry. J. Neurosci. Res., 86: 1944-1958. PMID: 18438914

Stirling, D.P., K. Khodarahmi, J. Liu, L.T. McPhail and C.B. McBride et al., 2004. Minocycline treatment reduces delayed oligodendrocyte death, attenuates axonal dieback and improves functional outcome after spinal cord injury. J. Neurosci., 24: 2182-2190. PMID: 14999069

Stoll, G., S. Jander and M. Schroeter, 2002. Detrimental and beneficial effects of injury-induced inflammation and cytokine expression in the nervous system. Adv. Exp. Med. Biol., 513: 87-113. PMID: 12575818

Streit, W.J., S.L. Semple-Rowland, S.D. Hurley and R.C. Miller et al., 1998. Cytokine mRNA profiles in contused spinal cord and axotomized facial nucleus suggest a beneficial role for inflammation and gliosis. Exp. Neurol., 152: 74-87. PMID: 9682014

Stys, P.K., 2004. White matter injury mechanisms. Curr. Mol. Med., 4: 113-130. PMID: 15032708

Taoka, Y., K. Okajima, M. Uchiba, K. Murakami and S. Kushimoto et al., 1997. Role of neutrophils in spinal cord injury in the rat. Neuroscience, 79: 1177-1182. PMID: 9219976

Tator, C.H. and M.G. Fehlings, 1991. Review of the secondary injury theory of acute spinal cord trauma with emphasis on vascular mechanisms. J. Neurosurg., 75: 15-26. PMID: 2045903

Tator, C.H., 1998. Biology of neurological recovery and functional restoration after spinal cord injury. Neurosurgery, 42, 696-707. PMID: 9574633

Thithapandha, A., H.M. Maling and J.R. Gillette, 1972. Effects of caffeine and theophylline on activity of rats in relation to brain xanthine concentrations. Proc. Soc. Exp. Biol. Med., 139: 582-586. PMID: 5059048

Tobinick, E., 2010. Perispinal etanercept: A new therapeutic paradigm in neurology. Expert. Rev. Neurother, 10: 985-1002. PMID: 20518613

Torphy, T.J., 1998. Phosphodiesterase isozymes: Molecular targets for novel antiasthma agents. Am. J. Respir. Crit. Care Med., 157: 351-370. PMID: 9476844

Tseng, S., G. Pak, K. Washenik, M.K. Pomeranz and J.L. Shupack, 1996. Rediscovering thalidomide: A review of its mechanism of action, side effects and potential uses. J. Am. Acad. Dermatol., 35: 969-979. DOI: 10.1016/S0190-9622(96)90122-X

Tyor, W.R., N. Avgeropoulos, G. Ohlandt and E.L. Hogan, 2002. Treatment of spinal cord impact injury in the rat with transforming growth factor-beta. J. Neurol. Sci., 200: 33-41. DOI: 10.1016/S0022510X(02)00113-2
Van Rooijen, N. and A. Sanders, 1994. Liposome mediated depletion of macrophages: Mechanism of action, preparation of liposomes and applications. J. Immunol. Methods, 174: 83-93. PMID: 8083541

Van Rooijen, N. and E. Van Kesteren-Hendrikx, 2002. Clodronate liposomes: Perspectives in research and therapeutics. J Liposome Res 12, 81-94. PMID: 12604042

Wang, C.X., B. Nuttin, H. Heremans, R. Dom and J. Gybels, 1996. Production of tumor necrosis factor in spinal cord following traumatic injury in rats. J. Neuroimmunol., 69: 151-156. DOI: 10.1016/01655728(96)00080-X

Wang, C.X., C. Reece, J.R. Wrathall, A. Shuaib and J.A. Olschowka et al., 2002. Expression of tumor necrosis factor alpha and its mRNA in the spinal cord following a weight-drop injury. Neuroreport, 13: 1391-1393. PMID: 12167759

Watt, A.H., P.G. Reid, M.R. Stephens and P.A. Routledge, 1987. Adenosine-induced respiratory stimulation in man depends on site of infusion. Evidence for an action on the carotid body. Br. J. Clin. Pharmacol., 23: 486-490. PMID: 3580255

Wesberg, P., J. Hedner, T. Hedner, B. Perrson and J. Jonason, 1985. Adenosine mechanisms in the regulation of breathing in the rat. Eur. J. Pharmacol., 105: 59-67. PMID: 6099272

Whitaker, C.M., E. Beaumont, M.J. Wells, D.S. Magnuson and M. Hetman et al., 2008. Rolipram attenuates acute oligodendrocyte death in the adult rat ventrolateral funiculus following contusive cervical spinal cord injury. Neurosci, Lett., 438: 200-204. DOI: 10.1016/j.neulet.2008.03.087

Yan, P., Q. Li, G.M. Kim, J. Xu and C.Y. Hsu et al., 2001. Cellular localization of tumor necrosis factoralpha following acute spinal cord injury in adult rats. J. Neurotrauma, 18: 563-568. PMID: 11393259

Yin, Y., Q. Cui, Y. Li, N. Irwin and D. Fischer et al., 2003. Macrophage-derived factors stimulate optic nerve regeneration. J. Neurosci., 23: 2284-2293. PMID: 12657687

Young, W., 1993. Secondary injury mechanisms in acute spinal cord injury. J. Emerg. Med., 11: 13-22. PMID: 8445198

Yune, T.Y., M.J. Chang, S.J. Kim, Y.B. Lee and S.W. Shin et al., 2003. Increased production of tumor necrosis factor-alpha induces apoptosis after traumatic spinal cord injury in rats. J. Neurotrauma, 20: 207-219. PMID: 12675973

Zhu, J., E. Mix and B. Winblad, 2001. The antidepressant and antiinflammatory effects of rolipram in the central nervous system. CNS Drug Rev., 7: 387-398. PMID: 11830756 